\title{
BMJ Open Perceptions about the implementation of physiotherapist prescribing in Australia: a national survey of Australian physiotherapists
}

\author{
Timothy David Noblet, ${ }^{1,2}$ John F Marriott, ${ }^{1}$ Taryn Jones, ${ }^{3}$ Catherine Dean, ${ }^{4}$ \\ Alison B Rushton ${ }^{\odot 5}$
}

To cite: Noblet TD, Marriott JF, Jones T, et al. Perceptions about the implementation of physiotherapist prescribing in Australia: a national survey of Australian physiotherapists. BMJ Open 2019;9:e024991. doi:10.1136/ bmjopen-2018-024991

- Prepublication history and additional material for this paper are available online. To view these files, please visit the journal online (http://dx.doi org/10.1136/bmjopen-2018024991).

Received 3 September 2018 Revised 2 April 2019 Accepted 3 April 2019

\section{Linked}

- http://dx.doi.org/10.1136/ bmjopen-2018-026327

Check for updates

(C) Author(s) (or their employer(s)) 2019. Re-use permitted under CC BY-NC. No commercial re-use. See rights and permissions. Published by BMJ.

For numbered affiliations see end of article.

Correspondence to Mr Timothy David Noblet; TDN818@bham.ac.uk

\section{ABSTRACT}

Objectives To explore: (1) the views of Australian physiotherapists regarding potential implementation of non-medical prescribing in Australia, (2) how the geographical location and health sector in which a clinician works may influence their perceptions and (3) the perceptions of Australian physiotherapists about how physiotherapist prescribing might impact the care that the profession can provide.

Design A cross-sectional descriptive survey using open and closed questions.

Setting Participants completed an online questionnaire. Participants 883 Australian Health Professionals Registration Authority (AHPRA)-registered physiotherapists, working across all states and territories.

Outcome measures An online questionnaire was developed by a panel of subject experts and pretested $(\mathrm{n}=10)$ for internal consistency. A hyperlink to the questionnaire was emailed to all members of the Australian Physiotherapy Association. A reminder email was sent 4 weeks later. Quantitative data were analysed descriptively, with use of absolute risk reductions (ARRs) and $95 \% \mathrm{Cls}$ to determine the likelihood that health sector or geographical location were associated with specific views. Thematic analysis enabled synthesis of the qualitative data.

Results $79.0 \%$ participants felt that physiotherapist prescribing should be introduced in Australia, with $71.2 \%$ wanting to train as prescribers. Clinical governance, risk management, regulation of clinicians and the development of an education framework were identified as priorities for implementation. Participants working in the private sector were significantly more likely to train as prescribers than those in the public sector (ARR 9.9\%; $95 \% \mathrm{Cl} 3.5$ to 16.4) or educational/research institutions (ARR 23.3\%; $95 \% \mathrm{Cl} 12.8$ to 33.8 ), with city dwellers significantly more likely to train compared with physiotherapists in remote regions (ARR 19.8\%; 95\% Cl 0.8 to 39.2). Physiotherapist prescribing was predicted to improve efficiency of healthcare delivery, access to medicines and reductions in healthcare costs.

Conclusions AHPRA-registered physiotherapists perceive that the introduction of autonomous physiotherapist prescribing would be beneficial for the Australian population and should be introduced. Decision makers should consider the results of this survey in conjunction
Strengths and limitations of this study

- First rigorous survey investigating the perceptions of Australian physiotherapists about the potential implementation of physiotherapist prescribing in Australia.

- Results provide the evidence required by the physiotherapy professional association, health departments and political leaders to inform clinically safe and economically sound decisions about redefining the scope of physiotherapy in Australia to include non-medical prescribing.

- Limitations are inherent with all survey-based research due to selection and response bias.

- It was not possible to determine why non-responders did not participate.

with cost-benefit and risk analysis when planning the introduction of physiotherapist prescribing.

\section{BACKGROUND AND RATIONALE}

Non-medical prescribing (NMP) has been used in clinical practice by a variety of professions for over 20 years. ${ }^{1}$ However, it was not until 2012 that in the UK, physiotherapists were first granted independent prescribing responsibilities. In July 2015, the Australian Physiotherapy Association (APA) in collaboration with the Australia Physiotherapy Council and Council of Physiotherapy Deans Australia and New Zealand submitted a proposal for the endorsement of registered physiotherapists for autonomous prescribing to the Physiotherapy Board of Australia. ${ }^{2}$ To prescribe medicines autonomously, a practitioner must be responsible for the assessment and diagnosis of the patient, prescribing drugs from a specified formulary within their individual scope of practice. The clinician manages ongoing therapy without the requirement of protocols or supervision. ${ }^{3}$ Difficulties in accessing medicines for Australians living in 
rural and remote areas alongside recognised health inequities between minority groups such as Aboriginal and Torres Strait Islander peoples were cited as key drivers for reform. Benefits of the implementation of prescribing by physiotherapists in Australia, such as the potential to increase access to medicines for health service users across all communities, ${ }^{2}$ are therefore anticipated.

The clinical and cost-effectiveness of NMP remains unclear, with a recent systematic review finding only minimal empirical evidence with unknown risk of bias ${ }^{4}$; nonetheless, its popularity in clinical practice continues to grow. ${ }^{5}$ A contemporary and robust mixed-methods systematic review of 50 moderate to good quality studies, investigating the barriers to and facilitators of independent NMP, identified conflict within a profession as a key barrier to successful implementation..$^{5}$ A united professional position regarding the adoption of innovative clinical practice was highlighted as essential to ensure the development of safe and high-quality practice. Divided opinion between individual clinicians, academics and professional managers/leaders may lead to confusion across the healthcare community, resulting in unwarranted negative thoughts and perceptions about NMP roles and responsibilities. Diverse perceptions regarding the implementation of physiotherapist prescribing and current physiotherapeutic pharmacological knowledge and practices have been reported in national evaluations in Nigeria, South Africa and the UK. ${ }^{6-9}$ Data from these evaluations have been used to influence national policy and the political drive towards or against the adoption of NMP within the physiotherapy profession in these countries. ${ }^{8}$ Acceptance and support for prescribing by the Australian physiotherapy profession will be required for successful implementation into local and national health systems. ${ }^{2}{ }^{10-12}$ It is therefore important that the views of Australian physiotherapists are understood in order to inform key stakeholders and decision makers about redefining the scope of physiotherapy to include NMP in Australia. To date, no evidence exists evaluating the Australian physiotherapy professions' views and perceptions about the potential use of NMP by physiotherapists in Australia.

\section{OBJECTIVES}

1. To explore the views of Australian physiotherapists about the potential implementation and use of NMP by physiotherapists in Australia.

2. To explore how the geographical location and health sector in which a clinician's works may influence the perceptions of Australian physiotherapists about the potential implementation and application of NMP by physiotherapists in Australia.

3. To explore the perceptions of Australian physiotherapists about how physiotherapist prescribing might impact the care that the physiotherapy profession can provide.

\section{Box 1 Participant inclusion criteria}

Physiotherapists registered with Australian Health Professionals Registration Authority.

Ability to read and understand written English.

Provision of consent to participate in the survey independently.

\section{METHODS}

A detailed study protocol was published to ensure transparency and reproducibility. ${ }^{13}$ The study is reported in line with an adapted version of the Standard Protocol Items: Recommendations for Interventional Trials statement, ${ }^{14}$ recommended by the SUrvey Reporting GuidelinE. ${ }^{15}$ This article reports the data collected from registered physiotherapists from a larger study evaluating both registered and student physiotherapists in Australia. ${ }^{13}$ The data collected evaluating the views and perceptions of student physiotherapists about the implementation of physiotherapist prescribing in Australia are presented in the related article published independently. ${ }^{16}$

\section{Survey design}

A cross-sectional online descriptive survey design enabled the collection of empirical data across Australia. ${ }^{17-19}$ An online questionnaire was developed using Qualtrics (Qualtrics, Provo, Utah, USA), thus enabling Australian-wide participation with no geographical or time zone constraints. ${ }^{172}$

\section{Participants}

Participant inclusion criteria are described in box 1 . According to data published by the Physiotherapy Board of Australia, 30004 physiotherapists were registered with the Australian Health Professionals Registration Authority (AHPRA) at the time of the survey. ${ }^{21}$

\section{Procedure}

AHPRA privacy policy ${ }^{22}$ prohibits approaching AHPRA-registered physiotherapists directly. Therefore, an advertisement containing a link to the online survey was emailed to all members of the APA, including all clinical and professional networks. A reminder advertisement was sent via email 4 weeks after the initial email to promote participation in the survey. ${ }^{17} 1920$ IP addresses were not saved to ensure participant anonymity. The APA membership was selected as the recruitment platform as it is representative of all physiotherapy specialties and levels of experience (qualified and student physiotherapists) across Australia, with 23153 members at the time of survey. ${ }^{23}$ Word-of-mouth referrals to the survey through professional networks were promoted in the email to facilitate capturing the views of non-APA members. ${ }^{17} 1920$ Data collection took place 1 March-30 April 2017. Participants accessed the questionnaire via the online link. Completion of the survey was anonymous and entirely voluntary. ${ }^{171920}$ Participant consent was gained using an online information and consent form. ${ }^{17-19}$ Researcher contact details were supplied to enable any questions or 
concerns to be answered prior to completing the online questionnaire. ${ }^{17-19}$

\section{Questionnaire development}

Data from a mixed methods systematic review examining the barriers to and facilitators of NMP internationally informed the questionnaire design and specific question inclusion. ${ }^{5}$ Questions were optimised through consultation with experts in the fields of physiotherapy, NMP and Australian state/federal law and health policy. ${ }^{17-19}$

The questionnaire consisted of four sections:

1. Demographic information including participants' age/gender/number of years qualified/specialty/ location.

2. Participants' perceptions of the positive and/or negative aspects of physiotherapist prescribing to the profession as a whole.

3. Participants' perceptions of the impact of physiotherapist prescribing to them as an individual.

4. Participants' perceptions regarding the potential wider impacts of physiotherapist prescribing.

Sections 1-3 used closed questions to collect quantitative data. Section 4 contained two open-ended questions to allow the participants to answer without limitation. ${ }^{17} 19$ In-built survey logic ensured that participants were shown questions that were pertinent to them based on their previous answers. Before completion, participants were encouraged to share any additional information that they deemed relevant, capturing useful insights not addressed elsewhere in the questionnaire. ${ }^{17-19}$

The questionnaire was piloted to test for internal consistency and optimise user experience. ${ }^{18}$ Ten participants $(\mathrm{n}=7$ registered physiotherapists, $\mathrm{n}=3$ student physiotherapists) were purposely sampled to represent the physiotherapy profession in Australia. ${ }^{17-19}$ Following the pilot, Anglo-Australian terminology was clarified, and small changes were made to the linguistics and survey logic. Pilot participants were not excluded from completing the final questionnaire. The final questionnaire can be found in online supplementary file 1 .

\section{Data storage}

All electronic data were stored in password-protected computer files only accessible by study investigators. Participants who disclosed personal details were additionally protected via coding on data files. ${ }^{17-19}$ The password-protected files will be retained for 10 years, satisfying ethical and university policies.

\section{Data analysis}

Demographic data (section 1) were tabulated, and primary descriptive analysis of the data was completed using IBM SPSS Statistics for Macintosh, V.22.0. Comparisons of proportions from questions in sections 2 and 3 , addressing objectives 1 and 2, were conducted using the PEDro CI calculator (http://www.pedro.org.au). ${ }^{24} 25$ Calculations of absolute risk reductions (ARRs) with $95 \%$ CIs were used to determine the likelihood that health sector or geographical location were associated with specific views. ${ }^{25}$ Thematic analysis was used to ensure the transparent synthesis of data addressing objective 3 , collected in section 4 of the online questionnaire. This analysis enabled the identification of key themes within a structured analytical framework. ${ }^{26}$ Answers were coded line-by-line using NVivo 11 software (QSR International, Melbourne, Australia) by one researcher (TDN) and were verified by a second researcher (TJ). Independently generated themes/subthemes were then examined by a panel of experts for confirmation and agreement. ${ }^{26}$

\section{Patient and public involvement}

The development of this study was informed by the experiences of patients and the general public acknowledged in the literature. Due to the study's objectives, patients and the general public were not used in design of the study or in participant recruitment. The results will be disseminated to all interested parties through publication and presentation at professional conferences.

\section{RESULTS}

\section{Demographics}

A total of 883 participants (3\% of all AHPRA-registered physiotherapists) completed the questionnaire. Demographic data are presented in table 1. Fifty-eight per cent of participants had been qualified for more than 10 years, with the majority of participants (88.4\%) gaining their primary professional qualification in Australia. The largest proportion of participants $(n=536$, $61 \%$ ) identified musculoskeletal physiotherapy as their specialty area of practice. Of those working clinically, $52 \%$ of participants worked in the private health sector. There were participants from every state and territory, with the majority practising in New South Wales $(\mathrm{n}=299,34 \%)$, Victoria $(n=234,27 \%)$, Western Australia $(n=130,15 \%)$ or Queensland $(n=115,13 \%)$. Seventy-eight per cent of participants worked in a major city.

\section{Participants' perceptions about the impact of physiotherapist prescribing on the physiotherapy profession}

Six hundred and eighty participants (79\%) reported that they strongly agreed or agreed that autonomous prescribing responsibilities should be introduced for physiotherapists in Australia, with 144 participants (12\%) against the introduction (figure 1). Potential benefits and concerns were identified.

The participants reported that physiotherapist prescribing could have a range of benefits in the Australian healthcare system (figure 1). The most commonly identified benefit was an improvement in the delivery of health services $(80.1 \%$; $n=707)$. Reduced costs of healthcare delivery to the consumer, as well as a reduction in the overall cost of healthcare and an improved consumer experience were also identified as potential benefits of NMP in Australia. Participants' concerns about the prescription of medicines by physiotherapists centred on quality and safety 
Table 1 Demographic data

\begin{tabular}{|c|c|}
\hline & $\begin{array}{l}\text { AHPRA- } \\
\text { registered } \\
\text { physiotherapists } \\
\text { n (\%) }\end{array}$ \\
\hline Total participants & $883(100)$ \\
\hline \multicolumn{2}{|l|}{ Gender ( $n=883$ answered) } \\
\hline Male & $366(41.4)$ \\
\hline Female & $517(58.6)$ \\
\hline \multicolumn{2}{|l|}{ Age ( $n=883$ answered) (years) } \\
\hline $17-29$ & $258(29.2)$ \\
\hline $30-39$ & $260(29.4)$ \\
\hline $40-49$ & $173(19.6)$ \\
\hline $50-59$ & $124(14.0)$ \\
\hline $60+$ & $68(7.7)$ \\
\hline \multicolumn{2}{|l|}{$\begin{array}{l}\text { Number of years qualified as a } \\
\text { physiotherapist ( } n=883 \text { answered) }\end{array}$} \\
\hline $0-4$ & $192(21.7)$ \\
\hline $5-9$ & $178(20.1)$ \\
\hline $10-14$ & 109 (12.4) \\
\hline $15-19$ & $101(11.5)$ \\
\hline $20+$ & $303(34.3)$ \\
\hline \multicolumn{2}{|l|}{$\begin{array}{l}\text { Country of primary qualification } \\
\text { ( } n=883 \text { answered) }\end{array}$} \\
\hline Australia & $781(88.4)$ \\
\hline $\begin{array}{l}\text { Overseas } \\
\text { (Belgium, Canada, Germany, Hong } \\
\text { Kong, India, Ireland, Italy, Mexico, } \\
\text { Netherlands, New Zealand, Philippines, } \\
\text { Portugal, Serbia, Singapore, South } \\
\text { Africa, Taiwan, UK and USA) }\end{array}$ & $102(11.6)$ \\
\hline \multicolumn{2}{|l|}{$\begin{array}{l}\text { Predominant physiotherapy practice } \\
\text { specialties: } \\
\text { (max of } 3 \text { specialties identified per } \\
\text { participant, } n=865 \text { answered) }\end{array}$} \\
\hline Amputees & $10(1.1)$ \\
\hline Burns/plastics & $9(1.0)$ \\
\hline Cardiorespiratory & $132(14.9)$ \\
\hline Chronic disease management & $100(11.3)$ \\
\hline Education & $58(6.6)$ \\
\hline Emergency department & $65(7.4)$ \\
\hline Gerontology/aged care & $115(13.0)$ \\
\hline Health promotion/public health & $10(1.1)$ \\
\hline Lymphoedema & $11(1.2)$ \\
\hline Mental health & $4(0.5)$ \\
\hline Musculoskeletal/orthopaedics & $536(60.7)$ \\
\hline Neurology & $81(9.2)$ \\
\hline Occupational health & $21(2.4)$ \\
\hline Paediatrics & $37(4.2)$ \\
\hline Pain & 105 (11.9) \\
\hline
\end{tabular}

Continued
Table 1 Continued

\begin{tabular}{|c|c|}
\hline & $\begin{array}{l}\text { AHPRA- } \\
\text { registered } \\
\text { physiotherapists } \\
\text { n (\%) }\end{array}$ \\
\hline Palliative care & $6(0.7)$ \\
\hline Rheumatology & $10(1.1)$ \\
\hline Rural generalist & $39(4.4)$ \\
\hline Women's health/continence & $53(6.0)$ \\
\hline Veterinary & $2(0.2)$ \\
\hline \multicolumn{2}{|l|}{ Health sector ( $n=872$ answered) } \\
\hline Public sector & $325(37.3)$ \\
\hline Private sector & $449(51.5)$ \\
\hline $\begin{array}{l}\text { Educational/research institute or } \\
\text { university }\end{array}$ & $49(5.6)$ \\
\hline Not-for-profit organisation & $36(4.1)$ \\
\hline Other & $13(1.5)$ \\
\hline \multicolumn{2}{|l|}{$\begin{array}{l}\text { Rural, Remote and Metropolitan Areas } \\
\text { classification }{ }^{39} \\
\text { ( } \mathrm{n}=783 \text { answered) }\end{array}$} \\
\hline Major cities of Australia & $679(77.8)$ \\
\hline Inner regional Australia & $113(12.9)$ \\
\hline Regional Australia & $58(6.6)$ \\
\hline Remote Australia & $20(2.3)$ \\
\hline Very remote Australia & $3(0.3)$ \\
\hline \multicolumn{2}{|l|}{ State or territory ( $\mathrm{n}=879$ answered) } \\
\hline Australian Capital Territory & $19(2.2)$ \\
\hline New South Wales & $299(34.0)$ \\
\hline Northern Territory & $7(0.8)$ \\
\hline Queensland & $115(13.1)$ \\
\hline South Australia & $64(7.3)$ \\
\hline Tasmania & $11(1.3)$ \\
\hline Victoria & $234(26.6)$ \\
\hline Western Australia & $130(14.8)$ \\
\hline
\end{tabular}

issues. In particular, concerns about whether physiotherapists have the knowledge required to train as a prescriber $(34.8 \%)$ and a potential increased safety risk to consumers $(34.1 \%)$ were raised. One-third of participants $(33.1 \%)$ were concerned that the expected remuneration for this service would not reflect the increased professional risk.

Figure 2 illustrates participants' opinions about the number of years of experience a physiotherapist should have prior to being permitted to train as a prescriber. The majority of participants felt that physiotherapists should have 3 years or more of experience $(68.4 \%)$, with $34.6 \%$ believing this should be at least 6 years.

Participants' perceptions about the impact of physiotherapist prescribing to them as an individual

Six hundred and eight participants $(71.2 \%)$ would be extremely likely $(\mathrm{n}=397,47 \%)$ or somewhat likely $(\mathrm{n}=211$, 
"I believe that autonomous prescribing responsibilities should be introduced for physiotherapists in Australia".

- Strongly Agree

- Agree

- Neither Agree nor Disagree

- Disagree

- Strongly Disagree

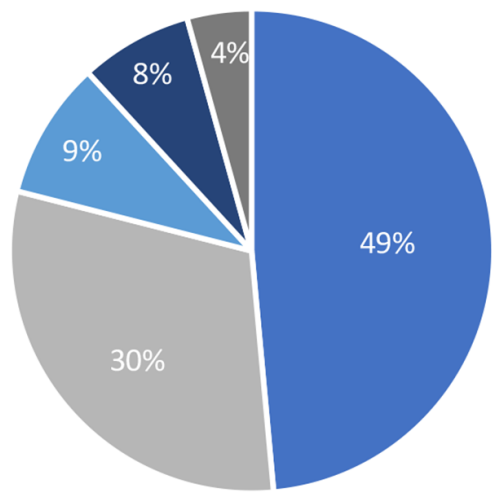

Potential benefits of physiotherapist prescribing in Australia

Improved efficiency of service delivery

Reduced costs of health care delivery to the consumer

Reduction in the overall costs of healthcare Improved consumer experience

Improved access for consumers to prescription...

Future proofing the Australian healthcare workforce Improved retention of clinicians

Potential for enhanced remuneration

Reduced safety risks to consumers

No benefits

Other

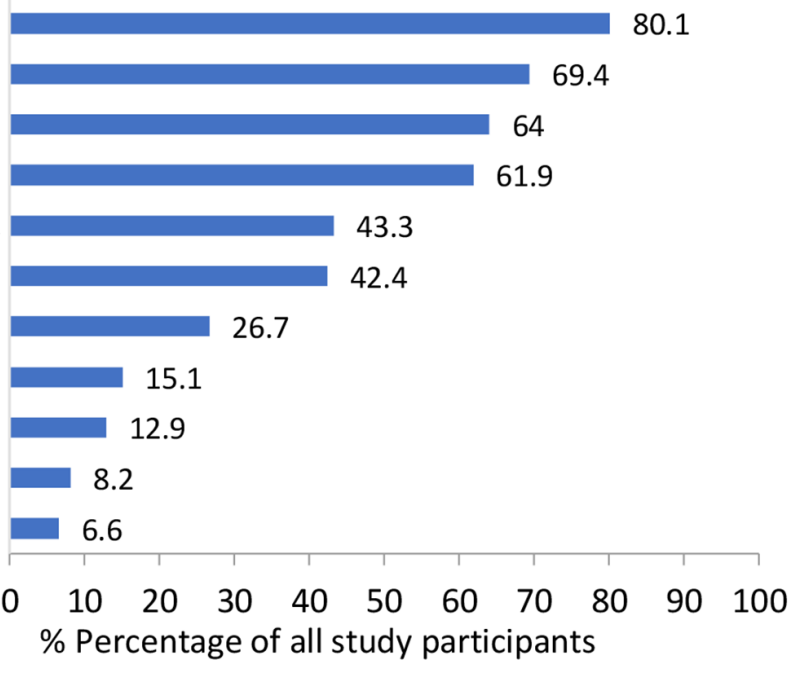

Figure 1 Physiotherapists' belief as to whether physiotherapist prescribing should be introduced in Australia; potential benefits and participants' concerns. 


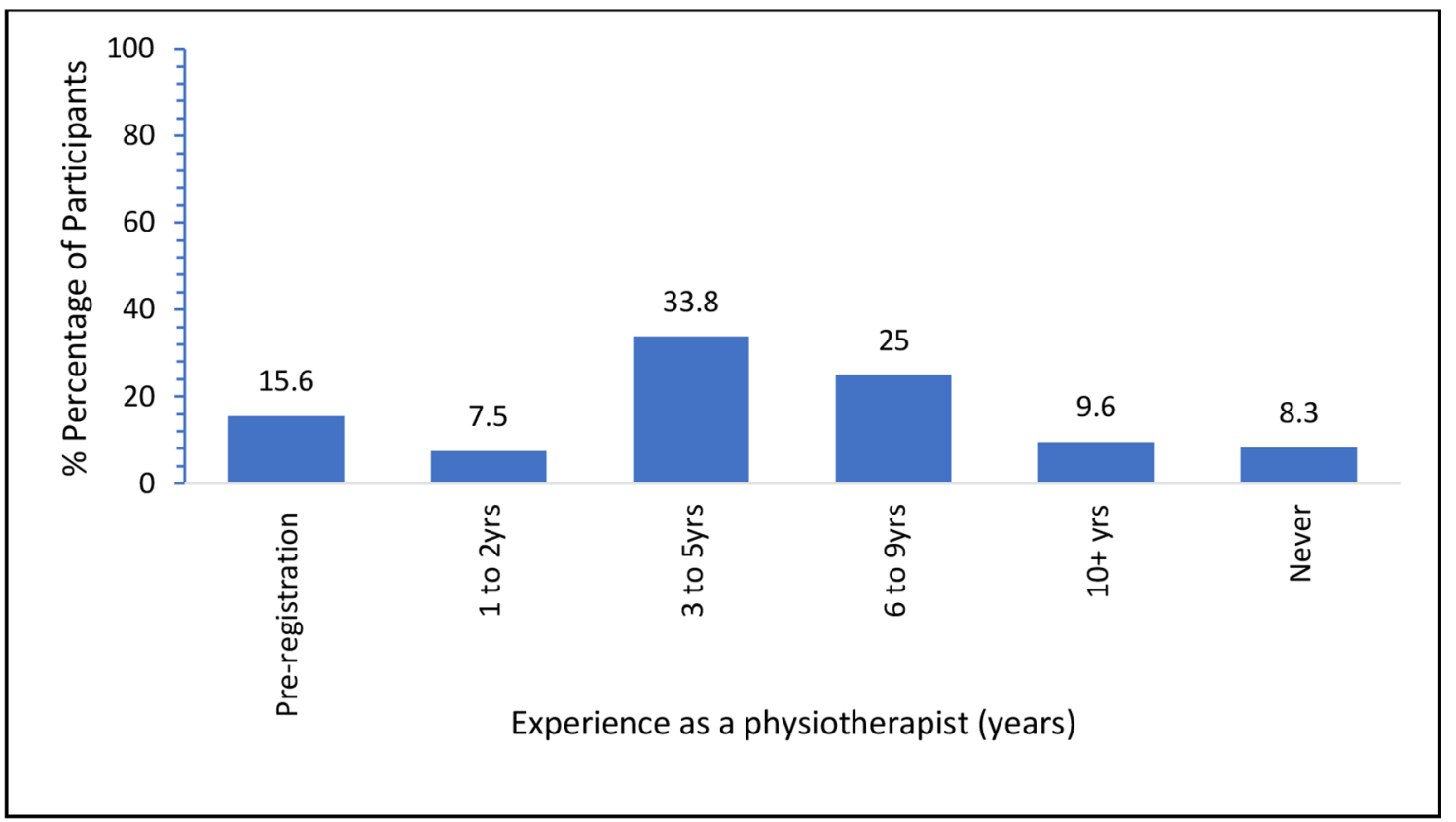

Figure 2 The number of years' experience a physiotherapist should have prior to being able to train as a physiotherapist prescriber.

$25 \%)$ to train as a prescriber if this were permitted, while 174 participants $(20.3 \%)$ would not. Figure 3 outlines the key motivators and deterrents among participants to train as a prescriber.

Key motivators cited included the ability to provide improved quality of care $(n=646,96.0 \%)$ and the improved professional reputation associated with NMP $(\mathrm{n}=416,61.8 \%)$. Some participants included increased job satisfaction $(\mathrm{n}=303,45.0 \%)$ and remuneration $(\mathrm{n}=125,18.6 \%)$ as motivating factors. Additionally, some participants $(\mathrm{n}=72,10.7 \%)$ reported being motivated by potential clinical and cost efficiencies for both for the consumer and healthcare provider through enhanced clinical pathways, improved access to medicines and optimisation of clinical knowledge.

The most common deterrent for training to be a prescriber was the belief that this will not change the care that the individual physiotherapist would provide to their patients $(n=152,61.8 \%)$. Concerns around an increased level of clinical responsibility were also highlighted as potential deterrents $(n=108,43.9 \%)$. Some participants felt that they did not have sufficient background knowledge to undertake the prescribing course $(n=76,30.9 \%)$. Additionally, participants reported that the cost of training or distance to travel to universities would be too great or that they were nearing retirement and did not want the additional stress of training to become a prescriber. Furthermore, it is noted that a small number of participants reported that they would not train as prescribers as they are employed in non-clinical roles $(n=35,14.2 \%)$.

\section{Influence of health sector and geographical location}

The percentage of participants from different health sectors and geographical locations, who agreed or strongly agreed with autonomous prescribing responsibilities being introduced for Australian physiotherapists and those who stated that they were extremely likely or somewhat likely to want to train as a prescriber are summarised in table 2.

Participants working in the private sector were significantly more likely to agree that autonomous prescribing responsibilities should be introduced for physiotherapist in Australia than those who work in education, not-forprofit organisations and the military (ARR 9.8\%, 95\% CI 0.8 to 20.2). No significant difference (ARR $1.7 \%$; $95 \%$ CI -4.0 to 7.6 ) was seen between participants who worked in the private or public healthcare sectors. Participants working in the private sector were significantly more likely to train as prescribers than those working in the public sector (ARR 9.9\%; 95\% CI 3.5 to 16.4) or other areas, such as within educational or research institutions (ARR 23.3\%; 95\% CI 12.8 to 33.8). A significantly higher proportion of participants in city regions expressed a wish to train as a prescriber compared with those in remote regions (ARR 19.8\%; 95\% CI 0.8 to 39.2). Those practising in cities (ARR 24.0\%, 95\% CI 5.8 to 43.9 ) and regional areas (ARR $19.5 \%, 95 \%$ CI 0.4 to 40.1 ) were significantly more likely to agree with the introduction of physiotherapist prescribing than those from remote regions. However, there was no significant difference (ARR 4.4\%, $95 \% \mathrm{CI}-2.2$ to 12.0 ) between participants who practise in major cities compared with regional areas.

\section{Wider impacts of physiotherapist prescribing}

Participants were asked to provide additional comments about how NMP may impact the overall level of care that the profession is able to provide. In total, 230 participants provided comments. 
How likely are you to want to train to become a Prescriber?

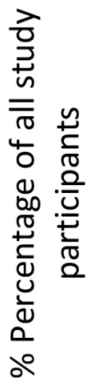

46.5

$\left.\begin{array}{c}40 \\ 20 \\ 0\end{array}\right]$

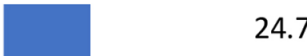

24.7

$\begin{array}{cccc}\text { Extremely likely } & \text { Somewhat likely Neither likely nor } \\ \text { unlikely } & \begin{array}{c}\text { Somewhat } \\ \text { unlikely }\end{array} & \begin{array}{c}\text { Extremely } \\ \text { unlikely }\end{array}\end{array}$

unlikely unlikely unlikely

Key Motivators for training to be a Prescriber

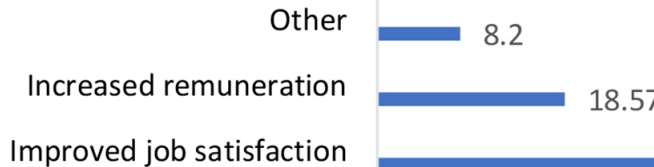

18.57

Improved professional reputation

Improved quality of care

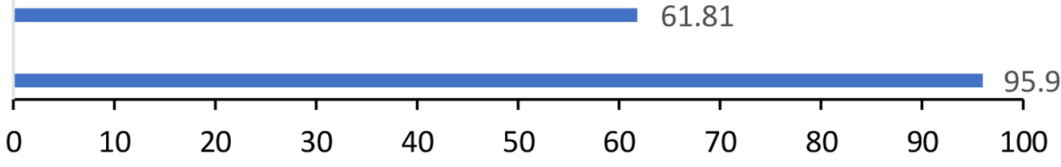

\% Percentage of the participants stating that they are likey to train as a Prescriber

Reasons why physiotherapists are unlikely to want to train as a Prescriber

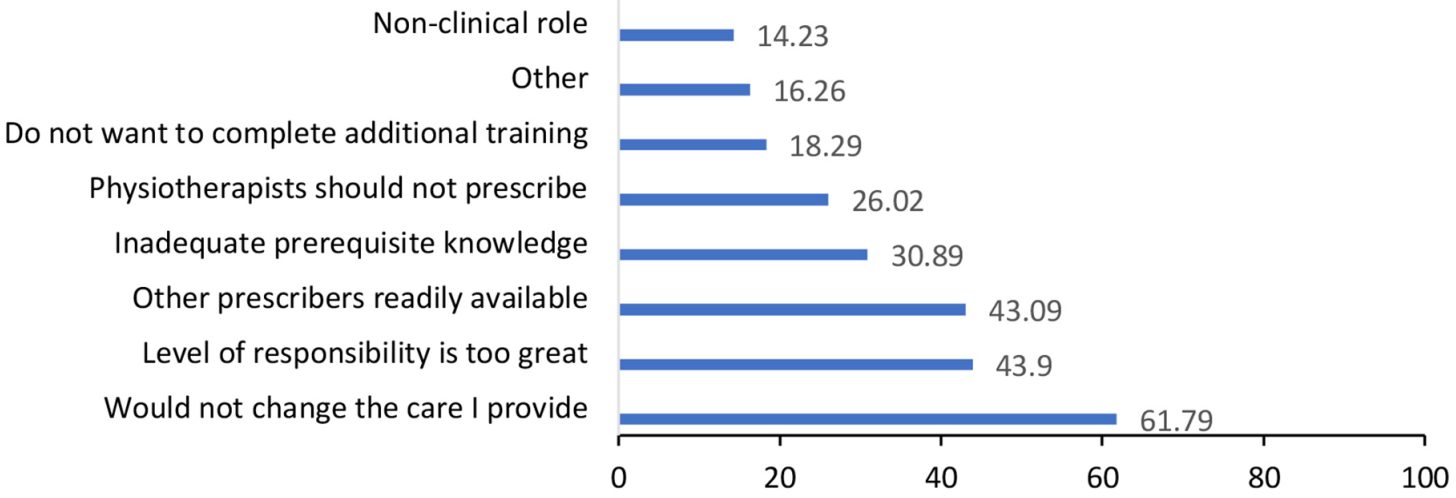

$\%$ Percentage of the participants stating that they are unlikey to train as a Prescriber

Figure 3 Likeliness to train as a prescriber: motivators and deterrents.

Four major themes were identified:

1. Clinical and cost-efficiency.

2. Access to prescription medicines.

3. Optimal therapeutics and clinical effectiveness.

4. Time management.

Table 3 lists the number of participants that reported or discussed each theme and provides illustrative quotations.

\section{Clinical and cost-efficiency}

One hundred and eighteen participants commented that the introduction of autonomous physiotherapist prescribing would have positive effects on both clinical and cost-efficiencies for patients, clinicians and the health economy. Participants identified the positive impact on the overall patient journey as a potential benefit of NMP 
by reducing unnecessary appointments with general practitioners (GPs), specialists and surgeons. Specifically, participants recognised the current frequency of referrals from physiotherapists to GPs for analgesic review, access to oxygen therapy, bronchodilators and antibiotics and ongoing pharmacological spasticity management. A common sentiment was that if physiotherapists could provide these services themselves, patients could have more timely access to appropriate medicines, which in turn would complement physiotherapeutic interventions and accelerate patient improvement/recovery. Participants also anticipated that NMP could reduce acute injury recovery times and minimise the risk of chronicity, which in turn could reduce pressures on medical services and end costs to the consumer, Medicare and private health insurers. Furthermore, the presence of physiotherapist prescribers in emergency departments and specialist multidisciplinary clinics was anticipated to reduce waiting times for patients, thus helping to meet performance measures set by governing bodies.

\section{Access to prescription medicines}

Seventy-one participants provided comments concerning potential improvements in accessing prescription medicines for all Australians regardless of geographic or other socioeconomic factors. Specifically, it was suggested that physiotherapist prescribers in rural and remote regions could issue prescription medications to patients who might otherwise have limited access to medical professionals. However, no participants from rural/remote regions identified this theme within their responses. Participants from metropolitan and regional areas expressed concerns that patients in rural and remote regions may struggle to navigate an overburdened and expensive healthcare system, frequently waiting for weeks and travelling great distances to see their GP for medications such as analgesics to supplement treatment from their physiotherapists. Participants from all locations identified potential benefits of NMP to healthcare consumers (regardless of location) whose principal healthcare practitioner is a physiotherapist, including persons with physical disabilities and those involved in sports where acute injuries are managed pitch-side by the team physiotherapist.

\section{Optimal therapeutics and clinical effectiveness}

Fifteen participants reported the potential for improved optimisation of medicines in line with physical and psychosocial interventions and therefore enhanced clinical effectiveness. Participants stressed optimal and appropriate use of analgesics across all specialties, especially where adjustments (escalation or de-escalation) to prescriptions are required in line with physiotherapeutic intervention. It was felt that that the multimodal skills and techniques used by physiotherapists would promote a more integrated use of medicines into the overall patient management, with medicines forming just one part of a more comprehensive and coordinated approach. Participants specialising in women's health echoed this 


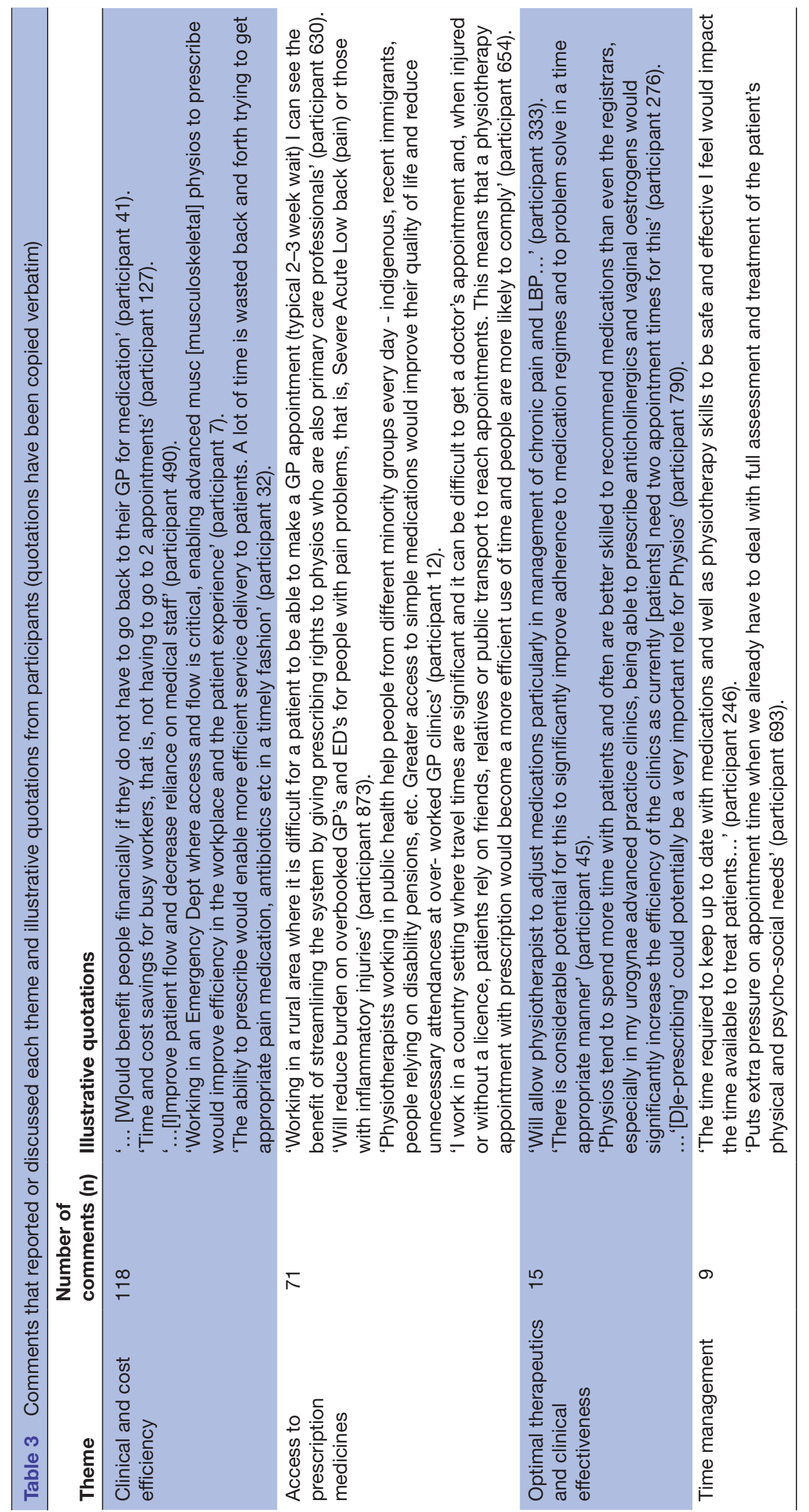


statement highlighting the appropriate use of anticholinergics and vaginal oestrogens necessary to holistically treat many of their patients.

Participants agreed that the close working relationships between physiotherapists and their patients, due to the comprehensive time spent completing physiotherapeutic interventions may be used to promote patients' compliance to their prescribed medicines. Physiotherapist prescribers with the appropriate knowledge and skills could legally reinforce the appropriate use of medicines, better recognising poor adherence, dependency, abuse or adverse side effects masquerading as conditions treated by physiotherapists.

\section{Time management}

Nine participants suggested that the time requirements needed to train as a physiotherapist prescriber and ongoing time required for continuous professional development (CPD) may be prohibitive to introducing NMP in Australia.

Likely, time away from clinical work for education and development and NMP duties were seen to potentially interfere with tasks currently performed by clinicians. Furthermore, participants felt that although greater efficiency and access to medicines may benefit heath consumers, time presently spent treating patients in the current scope of practice would be lost to procedures related to prescribing medicines. In other words, although NMP may decrease medical practitioners' workload, this would instead increase pressures on already understaffed physiotherapy departments and possibly even threaten clinical outcomes.

\section{Further insights}

The final question allowed participants to express any additional thoughts and views about physiotherapist prescribing that they deemed important and had not already been captured. Two hundred and sixty-six participants provided comments. Three major themes were identified:

1. Quality and safety: clinical governance, policies and procedures and education.

2. Professional issues.

3. Physiotherapy professional priorities.

Table 4 lists the number of comments that discussed each theme and subtheme, providing Illustrative quotations from participants.

\section{Quality and safety}

Two hundred and seventeen comments were received regarding quality and safety concerns around NMP. These focused on clinical governance, policies and procedures and educational requirements for prescribers.

One hundred and forty-four participants proposed that adequate clinical governance, policies and procedures should be in place for physiotherapist NMP to be successful. Participants identified the need for a clear scope of practice linked to a physiotherapy-centric formulary that is endorsed and regulated promoting transparency and safety. Participants raised concerns that statutory processes and procedures defining a limited formulary could quickly become outdated due to medical advances. Meanwhile, other participants identified that a limited formulary based around the profession's specialist areas of practice would be safest, protecting clinicians from pressures to prescribe out of scope. Participants were concerned that unless communication channels were maintained between physiotherapist prescribers and GPs, there is a risk that patients could shop around for prescriptions, potentially aiding the abuse of prescription medication and causing clinical incidents. Participants were also concerned that the increase in professional risk due to physiotherapist prescribing would lead to an increase in indemnity insurance premiums.

Seventy-three comments were received with regards to education. Participants recognised that the scope of practice must be absolutely clear, endorsed and underpinned by a robust clinical education framework. They felt that thought must be given to the process of assessment and selection of appropriately qualified assessors from outside the profession including medical doctors and pharmacists to ensure quality and safe practice among prescribers.

Access to prescribing courses for physiotherapists living in regional and remote areas was highlighted as a potential issue due to the distance to the nearest university. Participants recommended that the regulatory body should dictate compulsory annual CPD hours, and periodic reassessment of competency should be mandatory. Participants had varying opinions with regards to when physiotherapists should be able to train and qualify as prescribers; however, the participants agreed that current preregistration physiotherapy programmes should be updated to include pharmacology and therapeutics on their syllabi in preparation for the future.

\section{Professional issues}

Thirty-nine participants provided comments on important professional issues. Participants noted that the introduction of physiotherapist prescribing could change the 'physiotherapy brand', weakening the public's perception of physiotherapists as experts in manual therapy and exercise, leading to potential loss of patients to other emerging healthcare professions. It was suggested that a marketing campaign may be necessary to manage public expectation and minimise consumer confusion.

Interprofessional relationships between physiotherapists, medical practitioners and pharmacists were highlighted as being fragile. Participants warned that members of the Australian Medical Association would not support the introduction of physiotherapist prescribing, alluding to the possibility that medical doctors might see the introduction as a direct challenge to their authority and private businesses, leading them to reduce referrals to physiotherapy. Participants specifically identified the impact this may have on practice revenues in the musculoskeletal and sport specialties. That said, other participants 


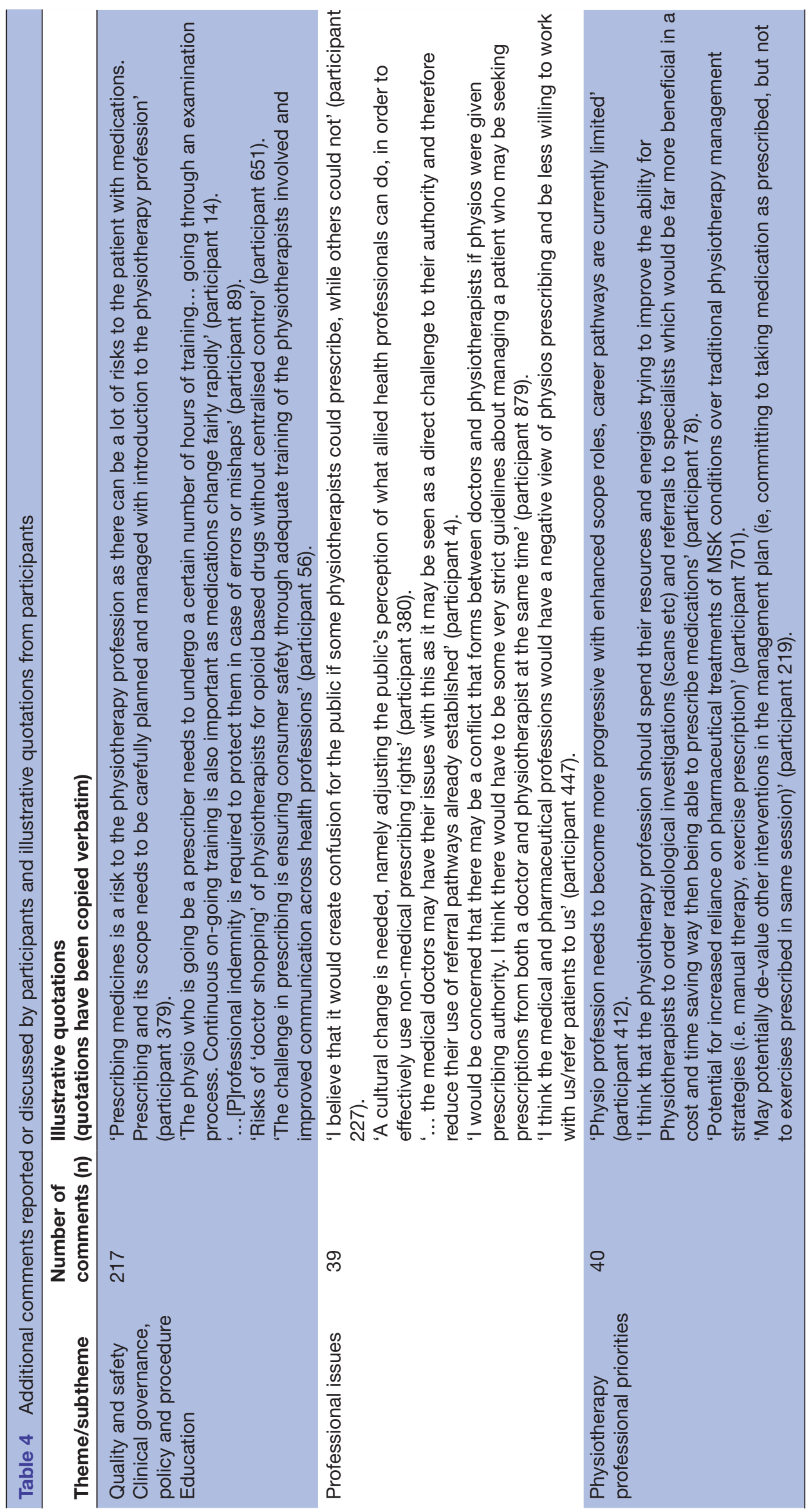


reported great support from medical colleagues and the greater multidisciplinary team, citing the streamlining of current clinical services and patient pathways, alongside improved access medicines as key reasons for positive interprofessional support. Participants warned that although these efficiencies would reduce service costs, establishing physiotherapist prescribing would require an initial coordinated investment to ensure appropriate governance, clinical education and safe/quality implementation across Australia.

\section{Physiotherapy professional priorities}

Forty participants commented on the profession's professional priorities. Participants described the risks of junior physiotherapists underdeveloping their traditional physiotherapy skills used to treat impairments and instead depending on medicines. To mitigate these risks, a robust career progression framework would need to be introduced to ensure ongoing high-level professional development across all specialties. To safeguard the good reputation of the profession, participants focused on maintenance of quality and safety for patients and clinicians. Physiotherapist prescribing should be introduced in a structured and organised manner with all physiotherapists supporting each other, even if they do not wish to prescribe themselves. Furthermore, participants also commented that the ability for physiotherapists to directly refer to specialist medical or surgical practitioners and ensuring appropriate patient rebates for imaging would have a positive clinical impact.

\section{DISCUSSION}

This is the first study to explore the perceptions of Australian physiotherapists regarding NMP by physiotherapists in Australia. The majority of physiotherapists agreed that autonomous prescribing responsibilities should be introduced for physiotherapists in Australia. Improvements in the efficiency of healthcare delivery, access to medicines and reductions in costs across the health economy were suggested as potential benefits. These findings concur with those reported by student physiotherapists in Australia as detailed in a related article,${ }^{16}$ as well as reflecting an evaluation of physiotherapist and podiatrist independent prescribers in the UK, ${ }^{27}$ strengthening the external validity and transferability of the results. Concerns regarding clinical safety and management of clinical risk were clearly identified throughout the quantitative and qualitative sections of the survey, supporting the results of an international multiprofession mixedmethods systematic review investigating the barriers and facilitators of the implementation and utilisation of NMP. ${ }^{5}$ The systematic review identified the need to address governance, safety, educational and financial factors prior to training prescribers to protect both patients and clinicians from poor practice, process and clinical pathways. ${ }^{5}$ To safely and effectively introduce physiotherapist prescribing, politicians, regulatory bodies, healthcare managers, clinicians and the APA, in consultation with experts and health consumers, must develop robust legislation, regulation, clinical governance and safety policies as well as well-defined education and career frameworks.

To ensure that physiotherapists are equipped to prescribe safely within a multimodal physiotherapeutic context, participants perceived that a contemporary, innovative and robust educational framework should be developed prior to the introduction of physiotherapist prescribing. This perception reflects contemporary educational literature that urges educators to carefully consider the ever-evolving healthcare system when designing curricula for physiotherapists. ${ }^{28}$ Transforming healthcare needs will require the next generation of physiotherapists to be ready to adapt to changes in consumer complexity and expectation, working within new models of care that are organised, funded and delivered in innovative ways. It has been postulated in the literature that a more flexible, broader and deeper clinical expertise will be required by physiotherapists if the Australian physiotherapy profession wishes to succeed as evidence-based and viable health providers in the integrated, value-driven health industry of the future. ${ }^{29}$

To guarantee quality development of physiotherapists across the profession, participants called for the creation of a contemporary career development framework into which prescribing would be integrated to safeguard mastery of traditional skills, govern quality practice and maintain the 'physiotherapy brand'. This appeal concurs with literature reporting that career frameworks within healthcare help the public understand different clinicians' knowledge, skills and roles within one profession, as well as providing purpose and direction for professionals, promoting engagement and job satisfaction. ${ }^{30}{ }^{31}$ Further, academic qualifications and increased clinical responsibility should lead to enhanced remuneration if physiotherapists are to adopt prescribing into their clinical practice, as a lack of remuneration has been recognised as a barrier to NMP across other professions. ${ }^{32-34}$ Improvements in recruitment and retention within the profession were anticipated due to improvements in job satisfaction for clinicians and greater recognition and professional reputation, echoing the findings of other NMP professions reported in the literature. ${ }^{32} 3536$

Physiotherapists working in cities and regional areas were consistent in observing that physiotherapist prescribing would improve access to medicines across all regions but would be specifically helpful in rural/ remote areas where access to medical prescribers may be limited. However, physiotherapists from rural/remote areas, although positive about the introduction of physiotherapist prescribing, were less likely to wish to train as prescribers, identifying potential increased risks when working in geographical isolation owing to a lack of clinical support. Due to a perceived lack of need in the present healthcare environment, participants felt that not all physiotherapists would benefit from undertaking a NMP course. Those working in close multidisciplinary 
teams with colocated prescribers, or those employed in non-clinical roles such as healthcare managers or academic physiotherapists were found to be less likely to wish to become prescribers than clinicians working in the public and private sectors. There was debate as to when and who should undertake the training, with no consistency as to whether education should be included in foundation level courses or become a postregistration qualification for those with a specified clinical experience. Furthermore, rural physiotherapists identified that the distance to universities may act as a barrier to training as a prescriber, highlighting the need for educators to consider flexible learning methods such as online education and video teleconferencing to fulfil the academic requirements of a NMP course. It is therefore imperative that a robust, fit for purpose, transparent and future proof education framework is developed to ensure unity within the Australian physiotherapy profession and assurance for all stakeholders that physiotherapists prescribers would be adequately prepared for practice.

Participants' perceptions that physiotherapist prescribing in Australia would reduce costs to their patients, healthcare services and to the health economy as a whole is supported by an economic review commissioned by the APA. The report predicts savings to the Australian health economy of over $\$ 9.22$ million per year if physiotherapist prescribing was implemented ${ }^{37}$; however, this is not currently reflected in the health economics literature. A robust low risk of bias systematic review investigating the clinical and cost-effectiveness of NMP found only one inadequately powered pilot randomised controlled trial investigating clinical effectiveness to date, concluding that the benefit of NMP to the health economy remains unclear. ${ }^{4}$ This gap in the literature highlights the need for robust, adequately powered economic evaluation to investigate the cost-benefits perceived by physiotherapists across Australia.

\section{Strengths and limitations}

This is the first study investigating the perceptions of AHPRA-registered physiotherapists about the potential introduction of NMP among physiotherapists in Australia, and so, alongside the data from student physiotherapists presented in the related article, provides an important overview of the current associated professional landscape. The data should be used to guide the APA, health departments and political leaders towards successful implementation of physiotherapist prescribing in Australia. As with all surveybased research, limitations are inherent due to selection and response bias. The survey was anonymous, so participants may have biased the results by completing the online questionnaire multiple times. Furthermore, physiotherapists with strong views or vested interests may be more likely to complete the questionnaire, meaning that their answers may not reflect the views of the wider profession.

A representative survey response rate (as per precursory power calculations) was achieved. ${ }^{13}$ Although only $3 \%$ of AHPRA responded, this reflected the response rate of a previous national evaluation of physiotherapists, ${ }^{37}$ where similarly, it was not possible to contact all registered physiotherapists directly due to the AHPRA privacy policy. Physiotherapists who were not APA members at the time of the survey would have been unaware of the questionnaire unless they were provided with a link to the questionnaire through professional networks. It is impossible to determine why $97 \%$ of AHPRA registered physiotherapists did not participate; therefore, the risk of bias remains unknown and should be considered when interpreting the results. In line with recent Australian regulatory data, ${ }^{38}$ the sample was representative of all registered physiotherapists in Australia in terms of age, gender and state in which they practise. Unfortunately, no national demographic data exist demonstrating the geographic location or health sector of registered physiotherapists' employment. It is therefore likely that the comparable demographic profile of the study's sample to contemporary national evaluations enhances generalisability of the data to the greater physiotherapist population in Australia and reduces risk of bias.

\section{CONCLUSION}

AHPRA-registered physiotherapists perceive that the introduction of autonomous physiotherapist prescribing would be beneficial for the Australian population and should be introduced. Acceptance of physiotherapist prescribing and the likelihood of physiotherapists to train as prescribers vary depending on location and the health sector in which a physiotherapist works. Legislation, regulation and governance around the use of physiotherapist prescribing all require careful consideration and consultation with experts and health consumers to ensure the safety and quality demanded by physiotherapy profession. Rigorous national educational frameworks should be developed within a transparent career development structure to ensure prescribing is used within a multimodal physiotherapeutic context, safeguarding the professional reputation of physiotherapy.

It is recommended that the APA, health departments and political leaders use the results of this study in conjunction with cost-benefit analyses, risk analysis as well as assessment of the health requirements and consultation with key stakeholders to redefine the scope of Australian physiotherapy to include NMP. Future research is required to investigate the concerns raised by participants. It would be valuable to interview current physiotherapist prescribers to interrogate the perceived benefits and concerns about physiotherapy prescribing identified by the Australian physiotherapists. Lessons learnt in the UK could thus be used to inform implementation internationally.

\section{Author affiliations}

${ }^{1}$ CPR Spine, School of Sports, Exercise and Rehabilitation Sciences, University of Birmingham, Birmingham, UK

${ }^{2}$ Faculty of Medicine and Health Sciences, Macquarie University, Sydney, New South Wales, Australia 
${ }^{3}$ Department of Health Professions, Faculty of Medicine and Health Sciences, Macquarie University, Sydney, New South Wales, Australia

${ }^{4}$ Department of Health Professions, Faculty of Medicine and Health Sciences, Macquarie University, Sydney, New South Wales, Australia

${ }^{5}$ School of Health and Population Sciences, College of Medical and Dental Sciences, University of Birmingham, Birmingham, West Midlands, UK

Contributors TDN is a clinical advanced practice physiotherapist and $\mathrm{PhD}$ candidate at the University of Birmingham (UK). ABR is a Reader in musculoskeletal rehabilitation sciences and lead supervisor. JFM is a professor of clinical pharmacy and cosupervisor. Both supervisors ensured the rigour of methods and analyses. CD is a professor of physiotherapy, and $\mathrm{TJ}$ is an associate professor of physiotherapy at Macquarie University (Australia). All authors have contributed to the content of this article. TDN wrote the first draft of this article and has worked with all authors to develop subsequent drafts. All authors prior to publication gave final approval. Patients and the general public were not involved in this study.

Funding The authors have not declared a specific grant for this research from any funding agency in the public, commercial or not-for-profit sectors.

Competing interests None declared.

Patient consent for publication Not required.

Ethics approval Ethical approval was granted by the Medical Sciences Human Research Ethics Committee (HREC), Macquarie University, Australia (Reference No: 5201600846), and verified by the Research Governance Officer at the University of Birmingham, UK (Reference No: ERN_16-1576) where the lead author is currently undertaking his $\mathrm{PhD}$.

Provenance and peer review Not commissioned; externally peer reviewed.

Data sharing statement Raw survey data from the study are available on request for up to 10 years postpublication. Please contact CPR Spine at the University of Birmingham, Birmingham, UK.

Open access This is an open access article distributed in accordance with the Creative Commons Attribution Non Commercial (CC BY-NC 4.0) license, which permits others to distribute, remix, adapt, build upon this work non-commercially, and license their derivative works on different terms, provided the original work is properly cited, appropriate credit is given, any changes made indicated, and the use is non-commercial. See: http://creativecommons.org/licenses/by-nc/4.0/.

\section{REFERENCES}

1. Cope LC, Abuzour AS, Tully MP. Nonmedical prescribing: where are we now? Ther Adv Drug Saf 2016;7:165-72.

2. APA. The Physiotherapy Prescribing Pathway: Proposal for the endorsement of registered physiotherapists for autonomous prescribing. Melbourne, Australia: APA, 2015.

3. HWA. Health Professionals Prescribing Pathway (HPPP) Project Final Report. Canberra, Australia: HWA, 2013.

4. Noblet T, Marriott J, Graham-Clarke E, et al. Clinical and costeffectiveness of non-medical prescribing: a systematic review of randomised controlled trials. PLoS One 2018;13:e0193286.

5. Noblet T, Marriott J, Graham-Clarke E, et al. Barriers to and facilitators of independent non-medical prescribing in clinical practice: a mixed-methods systematic review. J Physiother 2017;63:221-34.

6. Unger M, Lochner R. Pharmacology practice and South Africa physiotherapists - part two needs analysis. S Afr J Physiother 2006;62:18-22.

7. Unger M, Lochner R. Pharmacology practice and South African physiotherapists-part one. S Afr J Physiother 2005;61:21.

8. Teslim OA, Idowu TA. Perception of Nigerian physiotherapists on enlistment, legislation and benefits of supplementary prescribing. Am J Public Health Res 2014;2(5):1-5.

9. DOH. Final Stage Equality Analysis - proposals to introduce independent prescribing by physiotherapists. London, UK: DOH, 2012.

10. Watt S, Sword W, Krueger P, et al. Implementation of a health care policy: an analysis of barriers and facilitators to practice change. BMC Health Serv Res 2005;5:53.
11. Evans-Lacko S, Jarrett M, McCrone P, et al. Facilitators and barriers to implementing clinical care pathways. BMC Health Serv Res 2010;10:1.

12. i5 Health. Non-Medical Prescribing (NMP); An Economic Evaluation: NHS Health Education North West, 2015.

13. Noblet T, Marriot J, Jones T, et al. Views and perceptions of Australian physiotherapists and physiotherapy students about the potential implementation of physiotherapist prescribing in Australia: a survey protocol. BMC Health Serv Res 2018;18:472.

14. Chan A-W, Tetzlaff JM, Altman DG, et al. SPIRIT 2013: new guidance for content of clinical trial protocols. Lancet 2013;381:91-2.

15. Bennett C, Khangura S, Brehaut JC, et al. Reporting guidelines for survey research: an analysis of published guidance and reporting practices. PLoS Med 2010;8:e1001069.

16. Noblet T, Marriott J, Jones T, et al. Perceptions of Australian Physiotherapy Students about the Potential Implementation of Physiotherapist Prescribing in Australia: a national survey. BMJ Open 2019. Submitted for publication.

17. Hicks CM. Research methods for clinical therapists: applied project design and analysis: Elsevier Health Sciences, 2009.

18. Kelley K, Clark B, Brown V, et al. Good practice in the conduct and reporting of survey research. Int J Qual Health Care 2003;15:261-6.

19. Bowling A. Research methods in health: investigating health and health services: McGraw-Hill Education (UK), 2014.

20. Wright KB. Researching Internet-Based Populations: Advantages and Disadvantages of Online Survey Research, Online Questionnaire Authoring Software Packages, and Web Survey Services. J Comput Mediat Commun 2005;10.

21. Physiotherapy Board of Australia. Registration Data Table. 2016.

22. AHPRA. Privacy Policy. 2nd edn: AHPRA, 2014.

23. APA. 2016 Annual Report: Australian Physiotherapy Association. 2017.

24. Herbert R. Confidence Interval Calculator 2013, 2017. Available: http://www.pedro.org.au/english/downloads/confidence-intervalcalculator [Accessed 22 Jun 2017].

25. Newcombe RG. Two-sided confidence intervals for the single proportion: comparison of seven methods. Stat Med 1998;17:857-72

26. Thomas J, Harden A. Methods for the thematic synthesis of qualitative research in systematic reviews. BMC Med Res Methodol 2008;8:45.

27. Carey N, Stenner K, Gage H. Evaluation of physiotherapist and podiatrist independent prescribing, mixing of medicines, and prescribing of controlled drugs. London: Policy Research Programme, Department of Health, 2016.

28. Dean CM, Duncan PW. Preparing the Next Generation of Physical Therapists for Transformative Practice and Population Management: Example From Macquarie University. Phys Ther 2016;96:272-4.

29. APA. InPublic 2025: Australian Physiotherapy Association. 2015.

30. Hutton D, Eddy A. How was it for you? What factors influence job satisfaction for band 5 and 6 therapeutic radiographers. Radiography 2013;19:97-103

31. Pearce C, Marshman J. A framework for specialist nurses: Christine Pearce and Julie Marshman describe how a development framework offers specialist nurses a structured career pathway with clarified roles and standardised titles. Nursing Management 2008;15:18-21.

32. Cousins R, Donnell C. Nurse prescribing in general practice: a qualitative study of job satisfaction and work-related stress. Fam Pract 2012;29:223-7.

33. Hales A. Perspectives on prescribing: pioneers' narratives and advice. Perspect Psychiatr Care 2002;38:79-88

34. Ross JD, Kettles AM. Mental health nurse independent prescribing: what are nurse prescribers' views of the barriers to implementation? $J$ Psychiatr Ment Health Nurs 2012;19:916-32.

35. Kelly A, Neale J, Rollings R. Barriers to extended nurse prescribing among practice nurses. Community Pract 2010;83:21-4.

36. Downer F, Shepherd CK. District nurses prescribing as nurse independent prescribers. Br J Community Nurs 2010;15:348-52.

37. Deloitte Access Economics. Economic analysis of the implications of physiotherapists prescribing medication. Melbourne, Australia: Deloitte Access Economics, 2015.

38. Physiotherapy Board of Australia. Registrant Data. Canberra, Australia: AHPRA, 2016.

39. Welfare AloHa. Rural, regional and remote health: a guide to remoteness classifications. Canberra: AlHW.: AlHW, 2004. 